\title{
Introduction to Research Dialogue
}

\author{
Norbert Schwarz \\ University of Michigan, USA \\ Available online 27 June 2009
}

Issues related to self and identity were a prominent theme at the most recent ACR and SCP conferences and consumer researchers' longstanding interest in the role of identity in consumer behavior has seen a new surge of popularity, as all contributors to this issue's Research Dialogue note. The present target article provides a promising integrative perspective for this work. Drawing on research in cultural, social, cognitive, developmental, and personality psychology, Daphna Oyserman (2009a) presents a model of identity-based motivation that is compatible with current theorizing about the situated nature of human cognition, motivation, emotion, and behavior. She proposes that identities, although experienced as enduring, are highly context sensitive. Using a wide range of methods-from laboratory experiments and field studies to randomized interventions in schools - she shows that identities are dynamically constructed in context with important downstream effects on how people make sense of the world, which procedures they employ in doing so, and which behaviors they prefer and engage in. As her findings abundantly illustrate, how people think about themselves is as flexible as consequential, with positive or negative outcomes depending on minor contextual influences that can cue important identities.

In the first commentary, Sharon Shavitt, Carlos Torelli, and Jimmy Wong (2009) discuss Oyserman's identity-based motivation model in the context of a broad range of consumer research issues. They highlight relevant findings from their own work on cultural differences in consumer behavior (see Shavitt, Lalwani, Zhang, \& Torelli, 2006) and identify conditions under which product- and brand-based affordances may limit the dynamic construction of identities and their downstream effects. Next, Jennifer Aaker and Satoshi Akutsu (2009) use Oyserman's framework to explore the role of identity in giving, both in the form of donating money and volunteering time. In the final commentary, Amna Kirmani (2009) focuses on the relationship between identity, goals, and brands and highlights the role of perceived authenticity in others' responses to a consumer's identity-based choice. Oyserman's (2009b) response to this far reaching set of stimulating commentaries completes this Research Dialogue, which complements earlier issues on the role of culture (Shavitt, Lalwani, Zhang, \& Torelli, 2006), motivation (Higgins \& Scholer, 2009), mental construal (Trope, Liberman, \& Wakslak, 2007) and self-regulation (Baumeister, Sparks, Stillman, \& Vohs, 2008; Strack, Werth, \& Deutsch, 2006).

\section{References}

Aaker, J. L., \& Akutsu, S. (2009). Why do people give? The role of identity in giving. Journal of Consumer Psychology, 19(3), 267-270.

Baumeister, R. F., Sparks, E. A., Stillman, T. F., \& Vohs, K. D. (2008). Free will in consumer behavior: self-control, ego depletion, and choice. Journal of Consumer Psychology, 18, 4-13.

Higgins, E. T., \& Scholer, A. (2009). Engaging the consumer: The science and art of the value creation process. Journal of Consumer Psychology, 19 , $100-114$.

Kirmani, A. (2009). The self and the brand. Journal of Consumer Psychology, 19(3), 271-275.

Oyserman, D. (2009a). Identity-based motivation: Implications for actionreadiness, procedural-readiness, and consumer behavior. Journal of Consumer Psychology, 19(3), 250-260.

Oyserman, D. (2009b). Identity-based motivation and consumer behavior Journal of Consumer Psychology, 19(3), 276-279.

Shavitt, S., Lalwani, A. K., Zhang, J., \& Torelli, C. J. (2006). The horizontal/ vertical distinction in cross-cultural consumer research. Journal of Consumer Psychology, 16, 325-356.

Shavitt, S., Torelli, C. J., \& Wong, J. (2009). Identity-based motivation: Constraints and opportunities in consumer research. Journal of Consumer Psychology, 19(3), 261-266.

Strack, F., Werth, L., \& Deutsch, R. (2006). Reflective and compulsive determinants of consumer behavior. Journal of Consumer Psychology, 16, 205-216.

Trope, Y., Liberman, N., \& Wakslak, C. (2007). Construal levels and psychological distance: Effects on representation, prediction, evaluation, and behavior. Journal of Consumer Psychology, 17, 83-95.

E-mail address: nschwarz@umich.edu. 